\title{
Multiple Hemorrhagic Cerebral Cortical Lesions in Neuro-Behçet's Disease
}

\author{
Kazuyuki Saito, Takashi Watanabe and Shuta Toru
}

Key words: neuro-Behçet's disease, intracranial hemorrhage, cerebral venous thrombosis, magnetic resonance imaging

(Intern Med 56: 2377-2378, 2017)

(DOI: 10.2169/internalmedicine.8632-16)

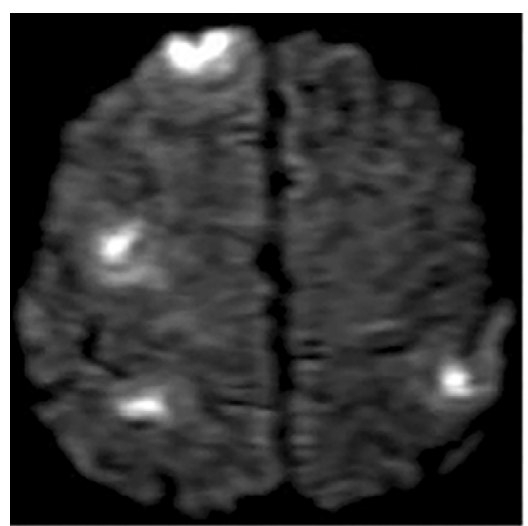

Picture A: DWI

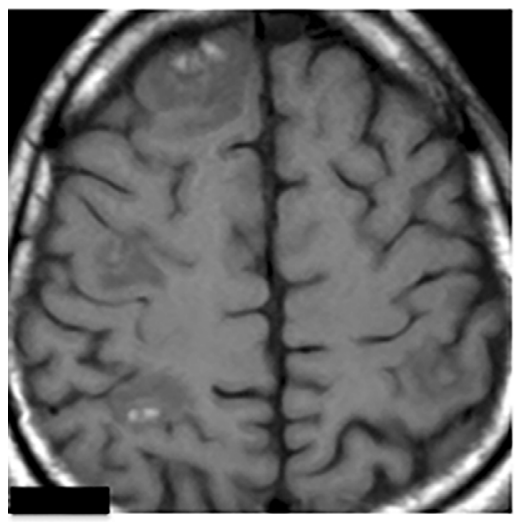

Picture C: T1WI

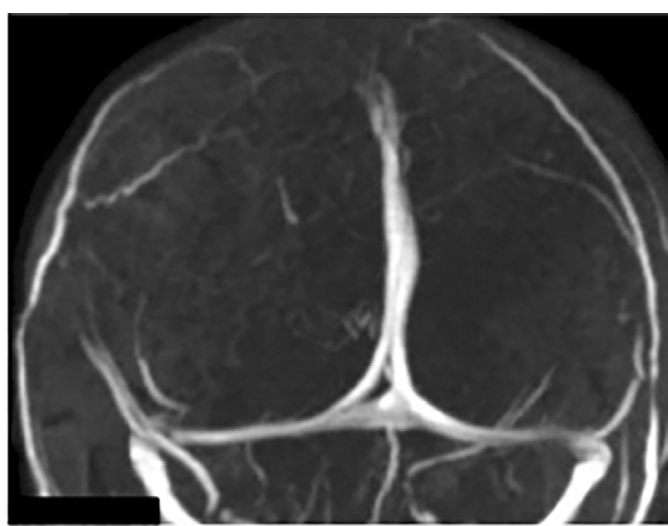

Picture B: MR venography

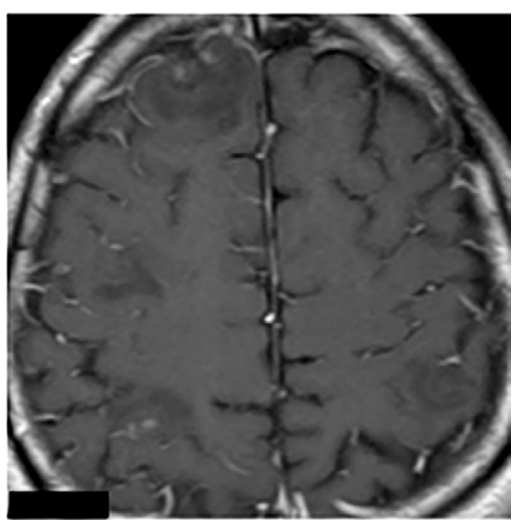

Picture D: gadolinium T1WI

Picture

A 27-year-old Japanese man presented with erythema nodosum and consciousness opacity of four days in duration. He had panuveitis and fever. A cerebrospinal fluid (CSF) analysis revealed $100 / \mathrm{mm}^{3}$ pleocytosis (polynuclear cells, $87 \%)$ and the elevation of interleukin-6 $(5,630 \mathrm{pg} / \mathrm{mL})$. Brain MRI demonstrated multiple hemorrhagic cerebral cor- tical lesions with gadolinium enhancement (Picture A, DWI; C, T1WI; D, gadolinium T1WI), but normal MR venography (Picture B). Cerebral venous thrombosis was not proven. The patient was positive for human leukocyte antigen-B51. He did not completely fulfil the International Study Group criteria for acute neuro-Behçet's disease 
(NBD) (1) because he lacked oral ulceration; however, the acute onset of neurological symptoms and CSF pleocytosis of $>6.2 / \mathrm{mm}^{3}$ both matched the criteria. He was treated with prednisolone $(1 \mathrm{mg} / \mathrm{kg} / \mathrm{day}$; the dose was tapered by $5 \mathrm{mg}$ per month and reduced to $5 \mathrm{mg} /$ day over two years) and infliximab $(5 \mathrm{mg} / \mathrm{kg}$ bimonthly) for one year, which resulted in remission. Although cortical lesions are rare in NBD (2), it is important to consider NBD when such atypical lesions are encountered.

The authors state that they have no Conflict of Interest (COI).

\section{References}

1. Hirohata S, Kikuchi H, Sawada T, et al. Clinical characteristics of neuro-Behçet's disease in Japan: a multicenter retrospective analysis. Mod Rheumatol 22: 405-413, 2012.

2. Farahangiz S, Sarhadi S, Safari A, et al. Magnetic resonance imaging findings and outcome of neuro-Behçet's disease: the predictive factors. Int J Rheumat Dis 15: 3142-3149, 2012.

The Internal Medicine is an Open Access article distributed under the Creative Commons Attribution-NonCommercial-NoDerivatives 4.0 International License. To view the details of this license, please visit (https://creativecommons.org/licenses/ by-nc-nd/4.0/).

(C) 2017 The Japanese Society of Internal Medicine Intern Med 56: 2377-2378, 2017 